\title{
Transdisciplinary System of Systems Development in the Trend to X4.0
}

\author{
John P.T. $\mathrm{MO}^{\mathrm{a}, 1}$ and Ronald C. BECKETT ${ }^{\mathrm{b}}$ \\ ${ }^{a}$ RMIT University, Australia \\ ${ }^{\mathrm{b}}$ Swinburne University of Technology, Australia
}

\begin{abstract}
Since the announcement of Industry 4.0 in 2012, multiple variants of this industry paradigm have emerged and built on the common platform of Internet of Things. Traditional engineering driven industries such as aerospace and automotive are able to align with Industry 4.0 and operate on requirements of the Internet of Things platform. Process driven industries such as water treatment and food processing are more influenced by societal perspectives and evolve into Water 4.0 or Dairy 4.0. In essence, the main outcomes of these X4.0 (where X can be any one of Quality, Water or a combination of) paradigms are facilitating communications between socio-technical systems and accumulating large amount of data. As the X4.0 paradigms are researched, defined, developed and applied, many real examples in industries have demonstrated the lack of system of systems design consideration, e.g. the issue of training together with the use of digital twin to simulate operation scenarios and faults in maintenance may lag behind events triggered in the hostile real world environment. This paper examines, from a high level system of systems perspective, how transdisciplinary engineering can incorporate data quality on the often neglected system elements of people and process while adapting applications to operate within the X4.0 paradigms.
\end{abstract}

Keywords. Industry 4.0; Water 4.0; Quality 4.0; System architecture; System of systems; Socio-technical systems

\section{Introduction}

The Industry 4.0 initiative has received increasing attention in recent years. The initiative defines future production environment specifications and allows customer and individual expectations to influence all phases of the product development lifecycle, such that last-minute changes are incorporated in the final product [1].

Advancement of the Internet, e-commerce, and social networks empowers consumers with more product details, including new product launches and in-depth product reviews. The global manufacturing supply chain is undergoing transformation to produce highly customised products tailored to individual needs by digitising and revolutionising daily business processes and administrative tasks with an associated initiative put forwarded by Bienhaus \& Haddud [2] as Procurement 4.0. Traditional engineering driven industries such as aerospace and automotive have incorporated Industry 4.0 with significant technological advancement and are heavily digitised to suit the operating requirements of the Internet of Things (IoT). Nevertheless, CasteloBranco et al [3] concluded from their study that only 5 countries in EU were

\footnotetext{
${ }^{1}$ Corresponding Author, Mail: john.mo@rmit.edu.au.
} 
comprehensively prepared for Industry 4.0 due to the need for a well-developed digital infrastructure coupled with strong big data analytical capabilities.

In this scenario, other industry sectors are forced to adopt similar approaches to satisfy increasingly sophisticated consumers by developing individualised business models. Beckett et al [4] explored emergent digital age quality management concepts under the headings of "Quality 4.0" and "Water 4.0" as a drive to improve the dairy industry. In this context, traditional engineering disciplines such as chemical and process engineering are combined with computer science, information systems and systems engineering disciplines, increased use of smart sensors in water and food quality monitoring was the key to this implementation. From this observation, it is convenient to note the phenomenon as "X4.0" where X can be any industry or process that becomes a term related to a paradigm shift on the common platform of IoT.

As the X4.0 paradigms are researched, defined, developed and applied, many real examples in industries have demonstrated the lack of system of systems design consideration, especially due to the nature of socio-technical processes and human participation. For example, process driven industries such as water treatment and food processing are influenced more by societal perspectives. Although earmarked to pursue Quality 4.0 and Water 4.0, training on IoT platform in water, food safety and environments, particularly with the use of digital twin to simulate operation scenarios and faults in maintenance still lags behind events triggered in the hostile real-world environment [5]. In the oil and gas industry, Lu et al [6] analyzed typical application scenarios upstream, midstream and downstream of the fuel supply chain. They concluded that "Oil and Gas 4.0" would succeed if industry personnel were trained to apply a highly digitised data-driven intelligence system to practical engineering.

This paper examines, from a high-level system of systems perspective, how transdisciplinary engineering can incorporate data quality on the often neglected system elements of people and process while adapting applications to operate within the X4.0 paradigms.

\section{The Challenges of X4.0}

With the advancement in IoT, global business networks rely more and more on the information technology and communication infrastructure to do business. The change in business processes triggers typical issues in X4.0 operations that include shorter product life cycle, more supply variability, difficult collaboration, risk to confidentiality, conflicts in intellectual property, opportunity loss, capacity constraints and others [7]. Simply drawing upon the advantage of increased amount and speed of data availability (or the big data) on the IoT platform is not enough to foster efficient and effective decision-making in the system of systems. A strategic framework is required to integrate the upstream and downstream managers that creates and adds value to the products or services that ends up in the hands of the consumers [8]. X4.0 systems have inherent challenges as IoT technologies become the main platform to do business. In this section, the issues of changing the business mode from traditional means to an Internet based system of systems are explored. 


\subsection{System complexity challenges}

Unlike a normal enterprise, a X4.0 environment is formed from a number of autonomous enterprises. According to O'Donovan et al [9], Industry 4.0 paradigm combined many legacy systems through industrial cyber-physical connectivity. However, incompatibility of technologies and architectures are still not fully resolved. Complexity existed in the "fog and cloud" interfaces resulting in latency and reliability issues, and the environment might not be optimised for ultimate performance.

Aziz et al [10] studied the implications of Industry 4.0 in New Zealand dairy industry - the leading industry in the country. They found that apart from quality control of dairy products, many other disciplines were inter-connected, including livestock management (number and health), transport, land use. Data transparency in terms of data flow and contextual integrity among operating units was important to ensure that corresponding business processes among trading partners could be developed and synchronised at a high level of visibility.

The global environment is dynamic and often affected by customer preferences such as seasonal requirements. Many customers expect a build-to-order strategy to be adopted among the participating enterprises. As cloud based system becomes the basis of communication among manufacturing enterprises, their interoperability will play a role of vital importance [11]. Risk-influencing determinants such as forecast uncertainty, demand variability, contribution margin, and time of delivery contributed to the responsiveness of the X4.0 system. Hence, modelling as a means of controlling the system's performance by design would be an important measure to manage the inherent complexity of the system of systems in X4.0 environment.

\subsection{Societal challenges}

Company operations in a X4.0 environment are effectively a system that consists of numerous organisations with different business perspectives (such as suppliers, manufacturers, distributors and customers). Although the usage of IoT is a common issue, social pressure emerged within and among organisations when the companies involved migrate to X4.0 paradigm. Turban et al [12] proposed a framework using Collaboration 2.0, which is a kind of social software. They investigated how it could improve with group decision making process. A "fit-viability" model was developed to assess the environment in which the social software tools could be useful.

Managers in the global business network should understand the institutional pressure applied and recognise they are all embedded in a broader ecosystem, when interacting with their X4.0 counterparts. For example, the United Nations [13] has declared the 2030 sustainability development requirements. Water accessibility and quality is one of the 17 goals that involve almost all disciplines and governments. Different types of institutional isomorphism, namely coercion, mimesis, and norms, could drive different levels of inhibition on the X4.0 system performance such as losing business opportunities. Likewise, Annosi et al [14] were interested in the attitude of owners and managers in Agriculture 4.0. The agricultural sector is primarily small and medium enterprises and the adoption of IoT is still limited. Perception of the utility of 4.0 technologies directly affected investment decisions.

For each business process there would be a number of headline systems that are relied upon. These interrelationships should be mapped out in a process known as situational awareness. By accurately mapping business processes to information 
systems, system operational risk could be identified leading to real business risk and subsequently vulnerability could be determined from the use of graphical representation of the tools [15].

Therefore, a crucial task in building a X4.0 system is to clearly define the social context with which the X4.0 style business is going to operate. In this circumstance, a transdisciplinary system design would be able to determine the physical and structural properties of collaboration, the culture, business practices, security processes and governance issues [16].

\subsection{Technological challenges}

An IoT-enabled global business network requires product information to be transferable in electronic format. A crucial condition to enable this capability is the compatibility of product lifecycle information models for decision making based on data gathered through different parts of the product development, manufacturing, sales and services processes [17]. Fundamental research is required into information systems models, smart embedded systems, short and long distance wireless communication technologies, data management and modelling, design for $\mathrm{X}$, adaptive production, statistical predictive maintenance and management of product end of life [18].

To complement the need for prototyping and physical testing, a virtual copy of the system (sometimes described as "digital twin"), that can interact with the physical counterparts in a bi-directional way, seems to be a promising enabler to replicate some X4.0 functions in real time for analysis and decision-making [19]. However, the control of the physical system by the "digital twin" has not been fully established.

Pacchini et al [20] attempted to develop an assessment model that could determine the readiness of a company in the implementation of Industry 4.0. Eight technology enablers were selected by reference to existing literatures. Similarly, Miranda et al [21] applied the $3 \mathrm{~S}$ concept, i.e. sensing, smart and sustainable, to Agri-Food 4.0. They were concerned about lack of design roadmaps that could enable development of $3 \mathrm{~S}$ based products for applications in agri-food production. The quality of data returned from these products has serious risks of affecting decisions in the business.

Inter-mixing of different legacy systems and continuous adoption of new technologies and techniques seem to be the norm for X4.0 systems. An open, agile system architecture for developing the operation platform is required.

\section{Requirements for a X4.0 System}

The need for a X4.0 system to overcome complexity, societal and technological challenges calls for a new system architecture that can be more broadly encompassing and versatile. Past system architectural constructs have proved to be too rigid for modern business practices [22]. Even back in 1989, the US Department of Defence [23] queried the need to send human pilots going into mission environment if a remotely piloted machine could be designed.

\subsection{Knowledge sharing and decision making in X4.0 Systems}

From system's perspective, an X4.0 system demands involvement of multiple systems with a variety of disciplines including engineering, computer science, information 
system and specialist user disciplines. Through IoT connection, people with different background knowledge and potentially different cultural norms, together with other stakeholders such as financial institutions, governments and certification authorities, will have strong influence on the development.

The dispersed environment nature of X4.0 essentially evolves into different types of business environments. In a known, ordered environment, repeatability allows for predictive models to be established and best practice identified. This is seen as the domain of process re-engineering pursuing efficiency, where the appropriate actions are categorize and respond. An example is the normal clinical treatment in medical system. In an unknown, ordered environment where cause and effect are not immediately evident (or may be known by only a few people), appropriate actions are analyse and respond. This is seen as the domain of systems thinking of the learning organization and the adaptive enterprise, where experimentation, expert opinion, factfinding, and scenario planning are combined. An example is the emergency hospital episodes [24].

In an unordered environment where complex relationships and interactions cause unexpected outcomes, appropriate actions are detect, categorise and respond. In this environment there may be a string of cause and effect relationships between the agents. Both the number of agents and the number of relationships make categorization or analysis difficult. Emergent patterns may be perceived but not predicted. An example is the joint military-civilian emergency response exercise where many issues had to be tracked in parallel [25].

In an unordered environment that seems chaotic, an appropriate response is to act, detect and respond. An example is an earthquake accident scenario where the immediate response is to act to minimise casualties and prevent further damages. In this situation, multiple decision-makers observe the same phenomenon from different points of view. Those most comfortable with stable order will try to create or enforce rules. Experts seek to conduct research and accumulate data. Politicians seek to increase the number and range of their contacts. Interestingly, dictators are eager to take advantage of this chaotic situation and seek absolute control. Collaborating to reach consensus on a series of small actions can change this situation [26].

Hence, a X4.0 paradigm is centred around the decision system at the core, and supported by a knowledge network with collaborating knowledge agents. The knowledge network supports the performance of tasks. It supports and is supported by the collection and distribution of information, and is populated by collaborating knowledge agents who may be individuals, teams or organizational groups.

\subsection{Modelling a X4.0 System}

Beckett and Daberkow [27] found that in the evolution of Industry 4.0 environment, some people might be displaced from their traditional occupations by intelligent agents and smart machines. At the same time there might be a shortage of people skilled in the development of these technologies. Hence, societal changes could see more people undertaking a succession of short-term project assignments. They represented Industry 4.0 and the related Work 4.0 paradigms in an integrated system as shown in Figure 1.

It is apparent from Figure 2 that X4.0 depends on data. The quality of data becomes an important consideration to prevent "garbage-in-garbage-out" problem. Managing data integrity is a system by its own right. This observation reflects close interactions between cyber-physical system and data analytic through numerous 
sensors and interfaces of analyses. Subsystem evolution is informed by ongoing technology and business research.

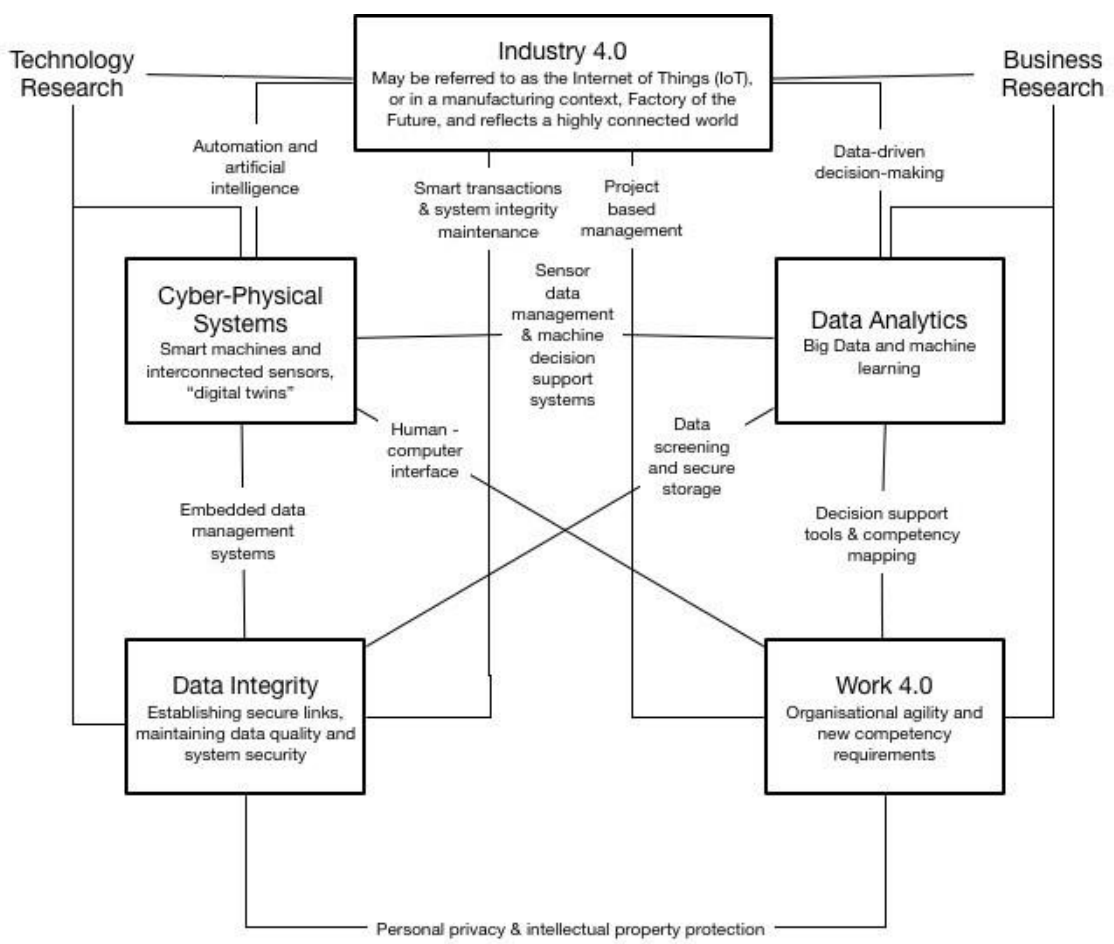

Figure 1. A system view of Industry 4.0 (source: [27]).

According to Figure 1, realisation of X4.0 requires the integration of four subsystems: cyber-physical systems, work 4.0, data analytics and data integrity. Hence, cyber-physical systems can be mapped to product product element and the work 4.0 system can be mapped to people element. Mapping of data analytic, data integrity and all interconnections may be viewed as a process element supporting the $3 \mathrm{P}$ interactions. This structure can form an initial conceptual X4.0 implementation among the companies involved in the $\mathrm{X}$ paradigm. Adopting an interacting network-centric system of systems view brings focus on decision-making either in responding to an emergency or in organizing alternative ways to meet customer requirements.

\section{System of Systems View of X4.0 in Transdisciplinary System}

From this view of Industry 4.0, it can be conceptualised that X4.0 is an elaboration of generically similar systems - a paradigm that exhibits a focus on cyber-physical, big data and engineering data analytics which will share similar characteristics with other businesses with the same focus. 


\subsection{System of Systems View}

A generic system could be represented as the coalition of three elements: people, process and product, in an operating environment. The 3PE model has been used in a quantitative sense focusing on assessing risks in engineering projects [28]. The product element in the 3PE model is the tangible hardware / software element that can give the "touch-and-feel". The people element includes all human participants to enable successful operation of the system. To use the product properly, a set of procedures, i.e. process, should be defined and followed. Needless to say, these elements are interacting among themselves. Without interactions, the product is not used by people, the people do not follow the process, the reaction of the product is unpredictable without a defined process. The $3 \mathrm{PE}$ model represents a standalone system in its system's environment.

Expanding from the single 3PE model as the fundamental system unit, Cook and Mo [29] represented the alliance, a consortium of companies engaged in a large defence project, as a system of systems as shown in Figure 2. It is necessary to note that only two organisations are drawn as illustration only.

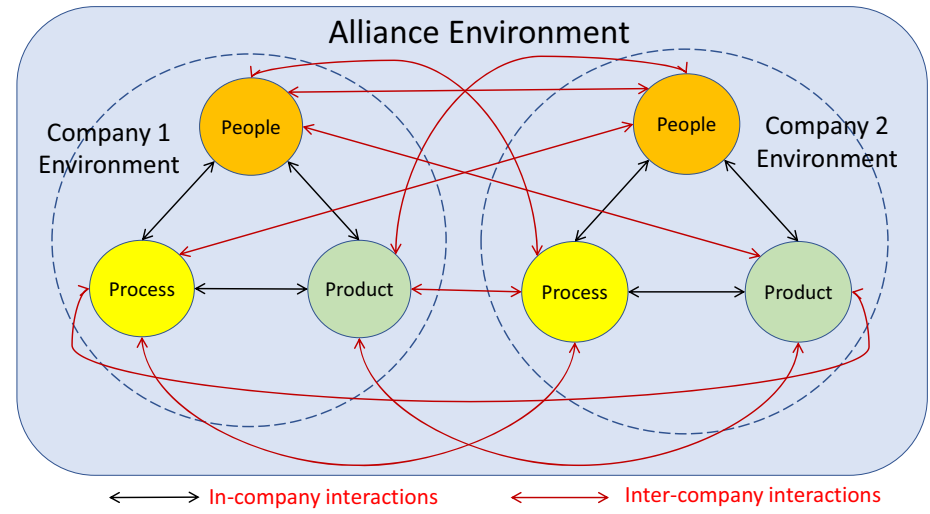

Figure 2. Alliance map with two partner organisations.

With X4.0 superimposed on top of the system of systems model, network-centric operations are about making connections and sharing information, i.e. interactions. Whilst frequent and recurring events may be described in terms of structured flows, it is the actors (people) who are driving the system's performance. For example, property management firms have operated tenant transaction systems for decades on web browser, e.g. collection of rents, distribution of payments to vendors, management of leases. The system of systems in this case should include network monitoring and control system for novice users who are unable to respond to disruption.

\subsection{Characteristics of a Transdisciplinary System}

The concept of transdisciplinary system has been explored as an extension of successful concurrent engineering practice that promotes innovative thinking and process. Sobolewski [30] presented a model of amorphous transdisciplinary compound service system that comprised micro-services and macro-services from multiple service providers. The transdisciplinary operating system provided amorphous front-end macro-services with corresponding collaborations of back-end service providers. The 
transdisciplinary process has been developed to solve ill-defined and socially relevant problems. In particular, implications for engineering research, practice and education have been investigated under transdisciplinary engineering banner [31].

In general, a transdisciplinary system is a complex system and can be conceptual modelled as a number of linked processes. It exhibits system characteristics in organisational, societal, cultural, and the usual engineering system structures that requires governance arrangements spanning multiple boundaries and comprises hierarchy between people, processes and products in a collaborative way [32].

With the X4.0 in place, the two evolutionary systems within the transdisciplinary system, viz, transdisciplinary development system and product service system are inevitably migrating onto IoT platforms. It would then be logical to think of incorporating a X4.0 system into each of the evolutionary systems as shown in Figure 3. The two evolutionary systems are not in conflict to each other. They exist at different times of the evolution lifecycle.

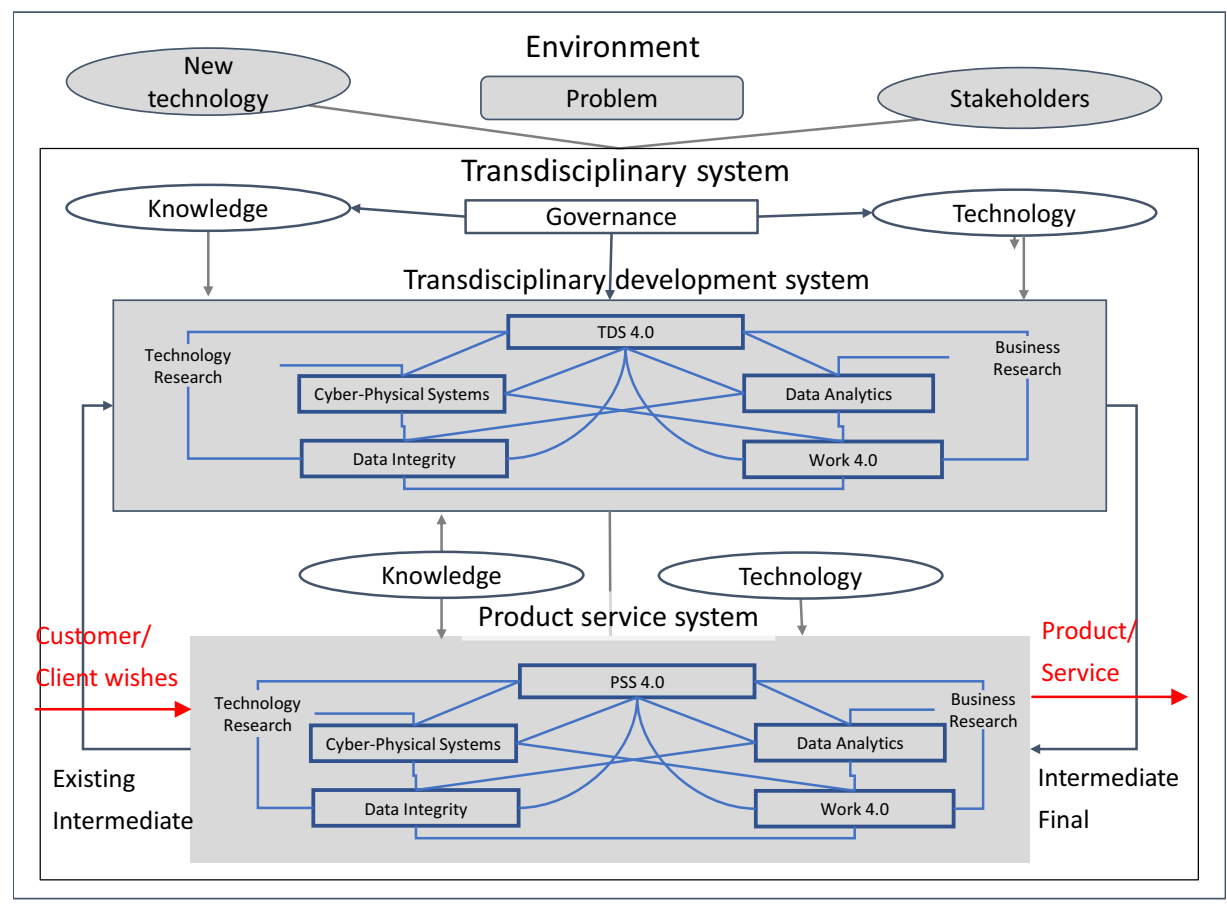

Figure 3. Adapted transdisciplinary engineering system model with X4.0.

The core activities of transdisciplinary development targets system that consists of multiple subsystems. The development subsystems form a coalition of different disciplines, social as well as technical, that are needed to solve the problem. The outcome is a product service system (PSS) that satisfies customer requirements. Within these evolutionary processes, the use of $\mathrm{X} 4.0$ related practices and facilities would greatly enhance communication and effectiveness of the transdisciplinary teams.

X4.0 paradigms are still evolving, and so are transdisciplinary systems. The forms and procedures differ significantly among different industries. It is still early to cite real examples of such systems. However, a close enough example has been reported two years ago [33]. A new internet based company Blamey Saunders Hears has gone 
through transdisciplinary development in a technology cluster precinct in collaboration with a similar company via internet. The outcome is a PSS of hearing aid products and services via IoT connection with experts. The authors also concluded that adopting a standard system design structure helped to define protocols in the system and streamline operations of the system significantly.

\section{Conclusion}

This paper reviews the fundamental requirements of X4.0 implementation within any industry paradigm $\mathrm{X}$, where the instantiation of $\mathrm{X}$ is expanding in different industry sectors around the world. By examining the characteristics of currently known fourth generation (i.e. 4.0) paradigms such as Quality 4.0, Water 4.0, Procurement 4.0, Oil and Gas 4.0, etc. it is realised that the use of IoT is immersive among the participants. The powerful communication platform facilitates socio-technical interactions and accumulates large amount of data in its operation.

The X4.0 system of systems structure is proposed with functional blocks cyberphysical system, data analytic, data integrity and work 4.0, and within each block we consider associated product, process and people roles in delivering requisite functionality. Based on this building block, it is conceptualised in this research that a X4.0 system can be the key platform of an evolutionary process of a transdisciplinary system in which the transdisciplinary development can be facilitated efficiently on IoT. As the transdisciplinary development progresses, the development outcome in the form of PSS can easily move to the operational stage to achieve the goal of customer satisfaction.

\section{References}

[1] F. Galati, B. Bigliardi. Industry 4.0: Emerging themes and future research avenues using a text mining approach, Computers in Industry, Vol.109, 2019, pp.100-113

[2] F. Bienhaus and A. Haddud. Procurement 4.0: factors influencing the digitisation of procurement and supply chains, Business Process Management Journal, Vol.24 No. 4, 2018, pp. 965-984

[3] I. Castelo-Branco, F. Cruz-Jesus, T. Oliveira. Assessing Industry 4.0 readiness in manufacturing: Evidence for the European Union, Computers in Industry, Vol.107, 2019, pp.22-32

[4] R.C. Beckett, R.L. Chapman, G. Berendsen, J. Dairymple. Quality 4.0 and water management practices. $17^{\text {th }}$ ANZAM Operations, Supply Chain and Service Management Conference, July 10 - 12 , 2019, Melbourne, Australia

[5] R.C. Beckett, N. Quispe-Chavez. Dairy process water utilisation and Industry 4.0, $17^{\text {th }} A N Z A M$ Operations, Supply Chain and Service Management Conference, July 10 - 12, 2019, Melbourne, Australia

[6] H. Lu, L. Guo, M. Azimi, K. Huang. Oil and Gas 4.0 era: A systematic review and outlook, Computers in Industry, Vol.111, 2019, pp.68-90

[7] R.C. Beckett, and H. Vachhrajani. Transdisciplinary Innovation: Connecting Ideas from Professional and Community Networks, Advances in Transdisciplinary Engineering, Vol. 5, 2017, pp. 737 - 744.

[8] S.S. Kamble, A. Gunasekaran, R. Sharma. Analysis of the driving and dependence power of barriers to adopt industry 4.0 in Indian manufacturing industry, Computers in Industry, Vol.101, 2018, pp.107119

[9] P. O’Donovan, C. Gallagher, K. Leahy, D.T.J. O’Sullivan. A comparison of fog and cloud computing cyber-physical interfaces for Industry 4.0 real-time embedded machine learning engineering applications, Computers in Industry, Vol.110, 2019, pp.12-35

[10] F. Aziz, S. Samsudin, N. Nambiar, U. Aziz, E. Li, R.Y. Zhong. Industry 4.0 in New Zealand dairy industry, International Journal of Agile Systems and Management, Vol.12, No.2, 2019, pp.180-197. 
[11] G. Pedone, I. Mezgár. Model similarity evidence and interoperability affinity in cloud-ready Industry 4.0 technologies, Computers in Industry, Vol.100, 2018, pp.278-286

[12] E.Turban, T.P. Liang, S.P. Wu. A framework for adopting collaboration 2.0 tools for virtual group decision making. Group decision and negotiation, Vol.20, No.2, 2011, pp.137-154.

[13] United Nations. Transforming our world: The 2030 Agenda for Sustainability Development. A/RES/70/1, Resolution adopted by the General Assembly on 25 September 2015, https://sustainabledevelopment.un.org/post2015/transformingourworld/publication

[14] M.C. Annosi, F. Brunetta, A. Monti, F. Nati. Is the trend your friend? An analysis of technology 4.0 investment decisions in agricultural SMEs, Computers in Industry, Vol.109, 2019, pp.59-71

[15] C.D. Wickens. Situation Awareness: Review of Mica Endsley's 1995 Articles on Situation Awareness Theory and Measurement, Human Factors, June 2008, pp. 397-403.

[16] J.P.T. Mo, R.C. Beckett. Architectural Knowledge Integration in a Social Innovation Context, Advances in Transdisciplinary Engineering, Vol. 7, 2018, pp.763-772

[17] J.P.T. Mo, M. Zhou. Tools and methods for managing intangible assets. Computers in Industry, Vol.51, No.2, 2003, pp.197-210

[18] A.B.L.S. Jabbour, C.J.C. Jabbour. M.G. Filho, D. Roubaud. Industry 4.0 and the circular economy: a proposed research agenda and original roadmap for sustainable operations, Annals of Operations Research, Vol.270, Iss.1-2, November 2018, pp 273-286

[19] C. Cimino, E. Negri, L. Fumagalli. Review of digital twin applications in manufacturing, Computers in Industry, Vol.113, 2019, paper no.103130

[20] A.P.T. Pacchini, W.C. Lucato, F. Facchini, G. Mummolo. The degree of readiness for the implementation of Industry 4.0, Computers in Industry, Vol.113, 2019, paper no.103125

[21] J. Miranda, P. Ponce, A. Molina, P. Wright. Sensing, smart and sustainable technologies for AgriFood 4.0, Computers in Industry, Vol.108, 2019, pp.21-36

[22] J.P.T. Mo, L. Nemes. Issues Using Enterprise Architecture for Merger and Acquisition, Chapter 9, in G. Doucet, J. Gøtze, P. Saha and S. Bernard (eds.), Coherency Management: Architecting the Enterprise for Alignment, Agility, and Assurance, AuthorHouse, Bloomington, ISBN 978-14389960783 (hard cover), 2010, pp. 235-262.

[23] US Department of Defence. Human engineering design criteria for military systems, equipment and facilities. MIL-STD-1472D, Document No. AD-A281 401, 1989

[24] P. Salmon, N. Stanton, D. Jenkins, G. Walker. Coordination during multi-agency emergency response: issues and solutions. Disaster Prevention and Management: An International Journal, Vol.20, No.2, 2011, pp.140-158

[25] R. Puikaew. Solving time critical newspaper production/distribution system: a case study of Matichon Newspaper Company in Thailand, International Journal of Agile Systems and Management, Vol.6, No.3, 2013, pp.284 - 306

[26] T. Kampanartkosol. Emergency response: an investigation on a possibility of establishing valuable flood protecting infrastructures in Bangkok, International Journal of Agile Systems and Management, Vol.6, No.2, 2013, pp. $175-202$

[27] R.C. Beckett, T. Daberkow. Work 4.0 and the identification of complex competence. Proceedings of the Fourteenth Midwest Association for Information Systems Conference, Oshkosh, Wisconsin, USA, May 21-22, 2019

[28] J.P.T. Mo, M. Cook. Risk analysis of the design of transportation enterprise network system for time critical manufacturing, Advances in Transdisciplinary Engineering, Vol. 5, 2017, pp. 898 - 905.

[29] M. Cook, J.P.T. Mo. Investigating into the Risks of Forming Alliance, Advances in Transdisciplinary Engineering, Vol. 7, 2018, Modena, Italy, pp.1135-1144

[30] M. Sobolewski. Amorphous transdisciplinary service systems, International Journal of Agile Systems and Management, Vol.10, No.2, 2017, pp.93-115

[31] N. Wognum, C. Bil, F. Elgh, M. Peruzzini, J. Stjepandić; W.J.C. Verhagen. Transdisciplinary systems engineering: implications, challenges and research agenda, International Journal of Agile Systems and Management, Vol.12, No.1, 2019, pp. 58 - 89.

[32] N. Wognum, W.J.C. Verhagen, J. Stjepandić. Trans-Disciplinary Systems as Complex Systems, Advances in Transdisciplinary Engineering, Vol. 5, 2017, pp.745-754

[33] J.P.T. Mo, R.C Beckett (2019) Architectural Modelling of Transdisciplinary System with Inherent Social Perspectives, Journal of Industrial Integration and Management: Innovation and Entrepreneurship, Vol.4, No. 4, 1950012. 